\title{
Questões de autoria para o retrato da Dama com Livro Junto a uma Fonte, da Coleção do MASP \\ Lorenzo Merlino' \\ DOI 10.20396/eha.vil4.3437
}

O objeto de pesquisa encontra-se na análise da atribuição da tela Retrato de Dama com Livro Junto a uma Fonte [Fig. 1], hoje na coleção do MASP, dada a Antoine Vestier (1740-1824), pintor contemporâneo dos conturbados anos revolucionários, pressupondo aprofundar o histórico da obra bem como sua interpretação estilística e iconográfica.

Vestier foi um pintor francês ativo no final do século 18 e início do século 19. Após um início autodidata na sua cidade natal de Avallon, Vestier se muda para Paris por volta de 1758, e entra como aprendiz no ateliê de Jean-Baptiste Pierre, então professor da Academia real de pintura já há 10 anos. Em algum momento a esta mesma altura ele vai se ligar ao mestre-esmaltador Pierre-Antoine Révérand, cuja filha Marie-Anne ele desposa em 1764, o que provavelmente explica sua produção posterior como miniaturista, atividade que ele exercerá concomitante com a de pintor por toda a vida, certamente como forma de contrabalançar as pouco frequentes encomendas de retratos que ele receberá, temática pictórica praticamente exclusiva durante toda a sua carreira.

Em 1774, Vestier vai participar como associado do Salão da Academia de Saint-Luc, instituição anterior à Academia oficial pois herdeira da medieva Communauté des peintres. Seu intento de adentrar nesta instituição se realiza em janeiro de 1776, mas ele nunca chegará a receber sua confirmação - logo em fevereiro Turgot, o Controlador Geral das Finanças, no intuito de modernizar a economia francesa, promulga um edito suprimindo todas as guildas e corporações, extinguindo assim a Academia de Saint-Luc, e com isso Vestier não obteve uma oficialização tão almejada.

Após retorno de uma breve viagem à Inglaterra, Vestier vai se ligar a um outro Salão, uma vez que seu acesso à Academia real não ocorria. Em 1779 o homem de letras Pahin de la Blancherie criara o Salon de la Correspondance, espécie de círculo literário e artístico que servia como ponto de encontro de intelectuais e artistas, acessível a artistas que não faziam parte das Academias oficiais, Ihes permitindo assim expor, em troca de uma pequena cotização, suas obras. O segundo Salão ocorre no verão de 1781, e Vestier expõe na ocasião 5 retratos. Em novembro ocorre um novo Salão, onde ele mostrará uma série de miniaturas, além

1 Mestre em História da Arte - IFCH, agência de fomento CAPES 


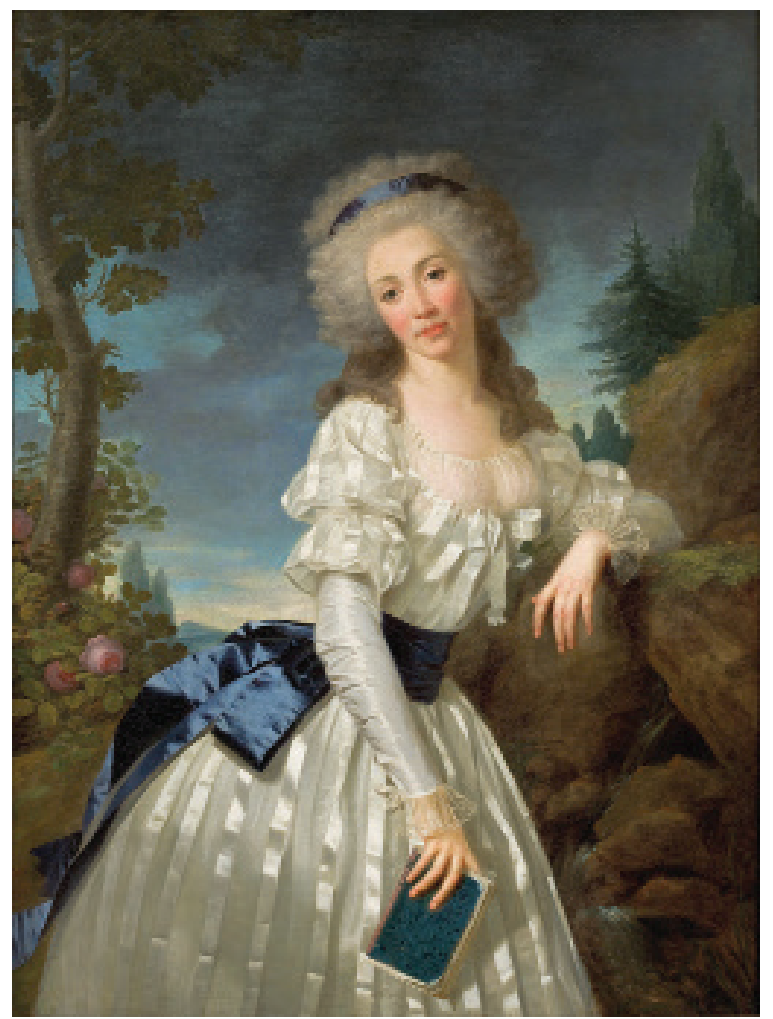

[Fig. 1] Retrato de Dama com livro junto a uma fonte, Antoine Vestier, ca.1785.

Óleo sobre tela, $130,5 \times 98 \mathrm{~cm}$. Museu de Arte de São Paulo Assis Chateaubriand, São Paulo. Disponível em: https://masp.org.br/ busca?search=vestier

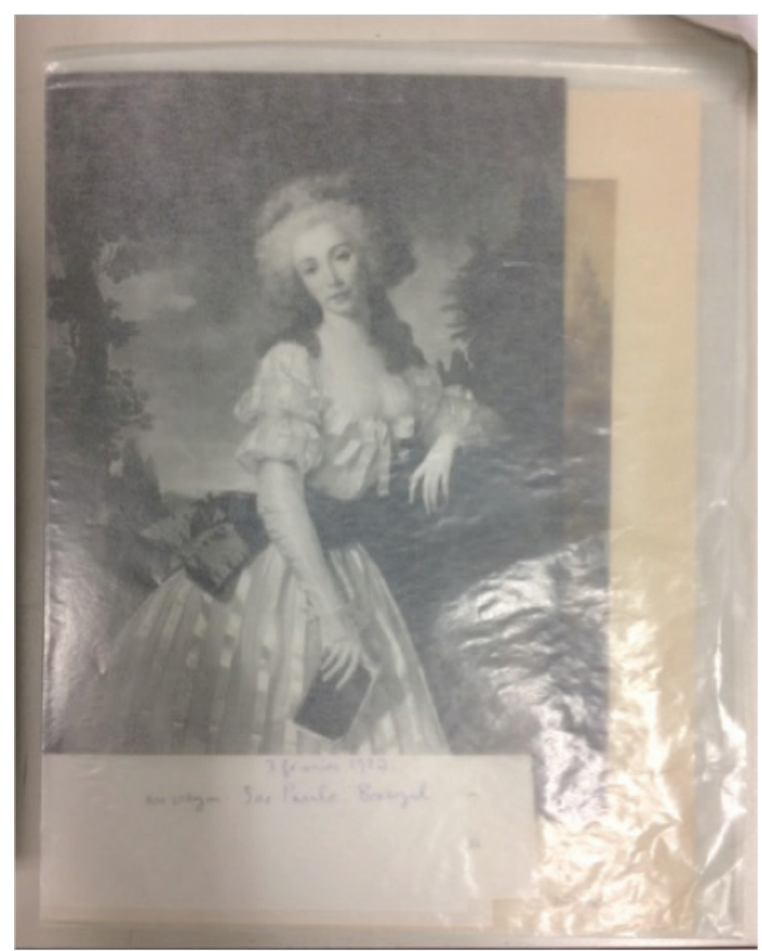

[Fig. 4] foto tirada pelo autor em junho de 2017 nos arquivos da Galeria Wildenstein de Paris referentes às pesquisas de Anne-Marie Passez.

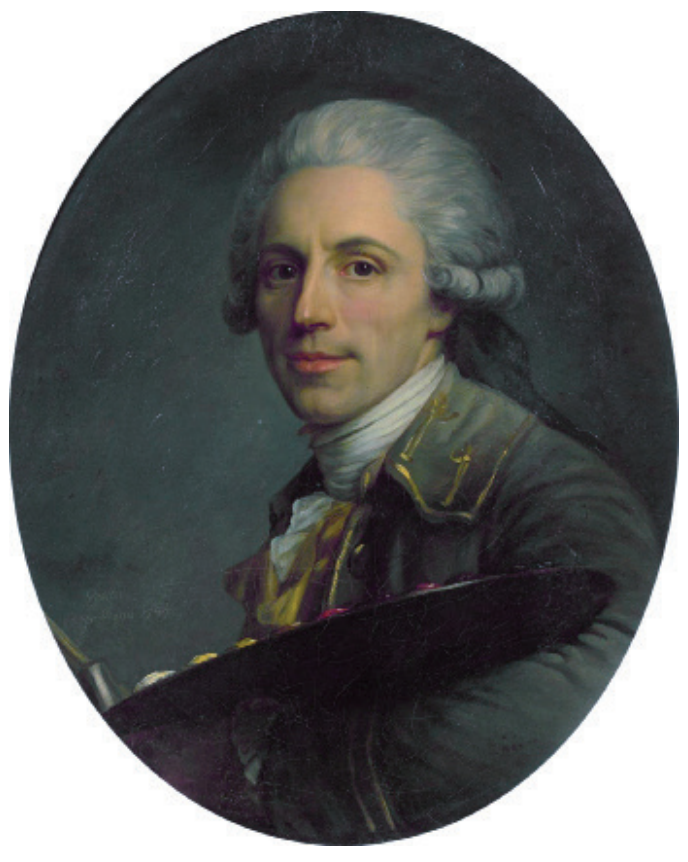

[Fig. 2] Autorretrato, Antoine Vestier, 1785.

Óleo sobre tela oval, $60,5 \times 49,5 \mathrm{~cm}$. Coleção privada (última venda pela Artcurial de Paris em 31/03/2016). Disponível em: http://www. alaintruong.com/archives/2016/03/31/33597220.html.

[Fig. 3] detalhe do Autorretrato, Antoine Vestier, 1785.

Coleção privada (última venda pela Artcurial de Paris em 31/03/2016). Disponível em: http://www.alaintruong.com/archives/2016/03/31/33597220.html

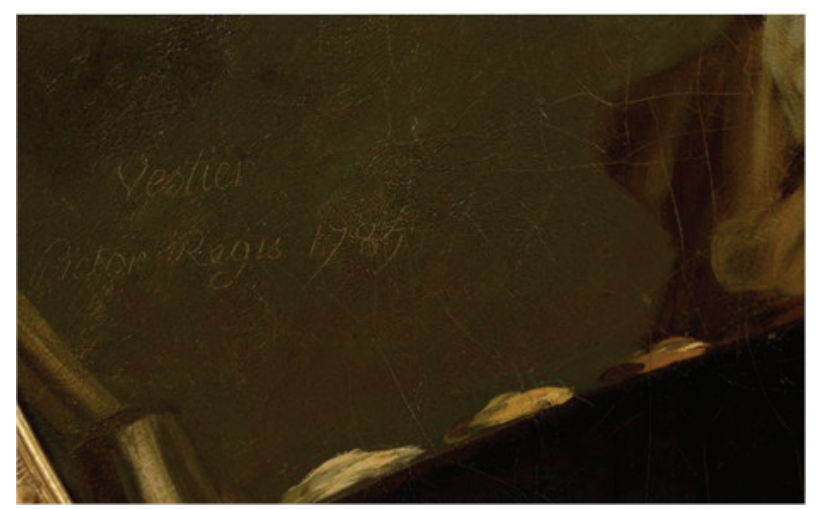


de 2 óleos. Em 1783 Vestier vai expor, nos 3 Salões ocorridos neste ano, 5 retratos, alguns deles já expostos nos Salões anteriores. Infortunadamente, neste mesmo ano, o Salon de la Blancherie se vê recusar qualquer disposição governamental de reconhecimento ou aprovação, cessando suas atividades no final de 1783. Novamente Vestier era vítima de revezes oficiais, que pela segunda vez Ihe impediam uma ascensão oficial por contratempos do destino.

Finalmente, em 1785, Vestier será aceito na Academia real de pintura, inicialmente como agréé, mas o que irá lhe permitir afinal expor nos Salões da instituição. Era o reconhecimento oficial que ele tanto esperara, e que lhe facultava ascender de posição no disputado contexto artístico francês deste final do século 18.

Após sua entrada definitiva na Academia real em 1786, Vestier passará a inscrever em suas telas, quase que constantemente, Vestier, Pictor Regis, conforme atestam as assinaturas em quase todos os retratos do mesmo período provável do quadro do MASP, o que demonstra o brio que sentia ao ter alcançado a posição de acadêmico após numerosos anos no exercício da profissão sem a chancela oficial [Fig. 2 e 3]

Portanto, um fato surpreendenteé a ausência de assinatura no retrato do MASP-Vestier dificilmente não assinava suas telas, orgul hoso que era de sua profissão e de sua aceitação na Academia. Das 120 pinturas repertoriadas em seu Catálogo Raisonné, 19 telas encontravam-se com localização desconhecida em 1989, o que impossibilitou a verificação de assinatura, e das restantes, apenas 11 não possuem seu assinalamento, mas quase todas com atribuições precisas. É contundente então que o retrato do MASP, fosse ele de autoria de Vestier, não possua qualquer tipo de marcação.

Adentrado na coleção do museu por doação de Assis Chateaubriand, o retrato do MASP foi adquirido pelo magnata através da Galeria Wildenstein, habituais fornecedores da instituição. Entretanto, o retrato não consta no Catálogo Raisonné de Vestier, circunscrito na biografia publicada em 1989 por Anne-Marie Passez, projeto financiado pela Fundação Wildenstein, instituição ligada à Galeria pois dela dependente - Passez intencionalmente não incluiu o retrato conforme comprovação que o autor obteve junto à própria galeria, em junho de 2017 [Fig. 4].

O quadro tampouco é mencionado nas notícias biográficas do Carnet Historique et Littéraire, feita pelo poeta André Foulon de Vaulx, e nem na palestra do Congresso Arqueológico da França de 1907, proferida pelo arquiteto Charles Nizet, e está ausente da biografia escrita em 1974 pelo historiador Jean-Claude Sueur, todas escritos que procuram estabelecer listagens das obras de Vestier. Quanto à sua proveniência anterior, a pintura pertenceu à coleção de Charles Chauncey Stillman, filho de James Stillman, de quem herdou a mesma.

James Stillman foi um poderoso homem de negócios americano do setor ferroviário, mercador e importante banqueiro, tendo sido presidente do National City Bank, o atual Citibank. Durante toda a sua 
carreira Stillman será um dos principais banqueiros mundiais, conhecido como um dos Wall Street's Big Three, participando eficaz e ativamente de todas as decisões que definiram o sistema financeiro dos Estados Unidos. Após o Pânico de 1907, e também por recomendações médicas que anteviam a possibilidade de um ataque nervoso após décadas de atividade profissional intensa, Stillman decide se afastar e se muda para Paris, instalando-se definitivamente na cidade a partir do verão de 1908.

Nos 6 anos seguintes, e com a ajuda de Mary Cassatt, ele vai adquirir uma considerável coleção de telas de pintores como Ingres, Nattier, Bellini, Rembrandt, Moroni e Ticiano. ${ }^{2}$ Mas seus interesses não vão se restringir somente à arte - Stillman será um ávido comprador dos couturiers da alta-costura parisiense do começo do século 20, sobretudo de Worth, adquirindo vários itens para as mulheres de sua família após exibições privadas com manequins, ocorridas nos salões de sua residência. ${ }^{3}$ Várias de suas escolhas em suas aquisições artísticas denotam este interesse particular pelas vestimentas, já que ele havia dito uma vez "sonhadoramente", que gostaria de ter sido estilista. ${ }^{4}$

Após a intensificação da Grande Guerra, Stillman retorna aos Estados Unidos no outono de 1917, vindo a falecer em março seguinte, em sua residência em Nova lorque. Sua considerável coleção foi então dividida entre seus 5 filhos, tendo o quarto deles, Charles Chauncey, ou CC como era chamado, herdado em particular o retrato que está na coleção do MASP.

Formado em Harvard, CC continuou o exemplo de seu pai, se tornando ele mesmo um refinado comprador de arte. Em 1918 torna-se fellow for life do Metropolitan Museum, e em 1921 cede por um período de cinco anos 14 das telas herdadas de seu pai, entre elas o retrato hoje no MASP, para que ficassem em depósito no museu, com a provável intenção de influenciar uma possível aquisição por parte do Metropolitan. Mas em vista do desinteresse do museu, CC inicia em 1925 tratativas com o Fogg Art Museum de Harvard, e acerta todos os detalhes da doação das 14 pinturas para o museu da universidade.

Entretanto, ele falece inesperadamente de uma crise de apendicite, em agosto de 1926, no retorno

\footnotetext{
2 WINKLER, John Kennedy. The first billion; the Stillmans and the National City Bank. Nova lorque: The Vanguard Press, 1934, p. 193. Um dos catálogos do MASP informa erroneamente que o retrato do Cardeal Cristoforo Madruzzo, de autoria de Ticiano, seria proveniente desta coleção. Catálogo do Museu de Arte de São Paulo Assis Chateaubriand. São Paulo: Prêmio Editorial, 1998. v. 2, p. 27. Entretanto, "um" retrato de Madruzzo que pertenceu a Stillman eram na verdade dois, dos dois sobrinhos deste Cardeal Madruzzo e de autoria de Moroni, e por diversas vezes citados como pendurados no salão principal de sua residência parisiense. A confusão pode ter ocorrido pois ambos, Cristoforo e seu sobrinho Ludovico, foram cardeais e bispos de Trento. The Stillman Collection of Paintings, on Exhibition \& Sale at The American Art Galleries, New York, 1927. Nova lorque: American Art Association Inc, 1927, p. 72. Os dois pendants encontram-se hoje, separados, no Art Institute de Chicago e na National Gallery of Art de Washington.

3 WINKLER, op. cit., pp. 160, 194 e 255 e BURR, Anna Robeson. The Portrait of a Banker: James Stillman, 1850-1918. Nova lorque: Duffield \& Company, 1927, pp. 310, 311 e 350 e HALE, Nancy. Mary Cassatt: A biography of the great American painter. Nova lorque: Doubleday \& Company, 1975, p. 219. Stillman tinha, desde a infância, apreciações para com a moda feminina, tendo criado figurinos para as bonecas de suas irmãs e frequentemente escrutinado as roupas e acessórios de sua mãe e irmãs, sendo por este motivo várias vezes repreendido por seu pai. WINKLER, op. cit., p. 29 e BURR, op. cit., pp. 35 a 37.
}

4 WINKLER, op. cit., p. 194. 
de uma viagem à Europa onde fora adquirir obras para o museu de Harvard, e seus filhos e seu executor testamentário decidem não honrar sua promessa de doação, que não havia sido efetivamente assinada.

A tela foi então vendida pela American Art Galleries em leilão ocorrido em 3 de fevereiro de $1927^{5}$, mas seu adquiridor não foi registrado, e o ou os proprietários da tela até sua aquisição por Assis Chateaubriand não são conhecidos. Essa então atribuição a Vestier não seria o primeiro erro na coleção dos Stillman - neste mesmo leilão uma tela atribuída a Bellini mostrou-se não ser do pintor veneziano, pois era uma cópia da Madonna Willys, hoje no MASP, feita pelo seu conterrâneo Rocco Marconi.

Não é incomum na historiografia da Arte que uma tela de Vestier seja desatribuída - uma suposta falta de uma forte personalidade artística explicaria o grande número de obras a ele erroneamente atribuídas. ${ }^{6}$ Passez frisa inclusive que seu estudo não relaciona as "falsas atribuições dadas a certos quadros de museus, nem da maior parte de sua obra conservada em coleções privadas". 7 A dificuldade de se atribuir telas a Vestier se deve sobretudo a uma problemática de se estabelecer características marcantes em sua produção, fato igualmente identificado por seus outros biógrafos. Diversas atribuições errôneas ao pintor puderam ser corrigidas no decorrer da História, e entre outros pintores já confundidos com Vestier encontram-se o alemão Tischbein, os franceses Lefèvre, Gérard e Voille, além de Vigée Le Brun, com quem as confusões talvez sejam as mais frequentes. ${ }^{8}$

Em vista de encontrar elementos que confirmassem que a tela do MASP não é de autoria de Vestier foi empreendido um processo comparativo entre o Retrato de uma dama e telas do pintor avallonês, uma vez que, como bem definiu o professor Coli em uma de suas recentes publicações:

um meio excelente para interrogar as obras são os procedimentos comparativos. Nada permite melhor entender uma obra do que outra obra. Associá-las mentalmente, ou visualmente, com reproduções sobre uma mesa, ou numa sala de museu, por semelhança oposição, ou indiferença entre elas é encontrar a 'terceira margem do rio'9

Ao compararmos, por exemplo, o único retrato feminino produzido certamente por Vestier onde a natureza é um pouco mais presente, intitulado La Belle ]ardinière [Fig. 5], com data de realização próxima da do quadro do MASP, as diferenças de procedimento são manifestas.

No retrato do MASP a paisagem tem um papel resolutivo na sensação geral do quadro, com a

5 The Stillman Collection of Paintings, op. cit., p. 92. A cifra "3.100"está grafada à mão no catálogo.

6 FOULON DE VAULX, André. Antoine Vestier, 1740-1824, notes et renseignements. In: Le Carnet Historique et Littéraire, tome VII (Janvier-FévrierMars 1901). Paris: Aux Bureaux de la Revue, 1901, pp. 228 e 230.

7 PASSEZ, Anne-Marie. Antoine Vestier. Paris: La Bibliothèque des Arts, Fondation Wildenstein, 1989, p. 78, tradução do autor.

8 Ibid., p. 78.

9 COLI, Jorge. O Corpo da Liberdade. São Paulo: Cosac \& Naify, 2010, p. 14. 


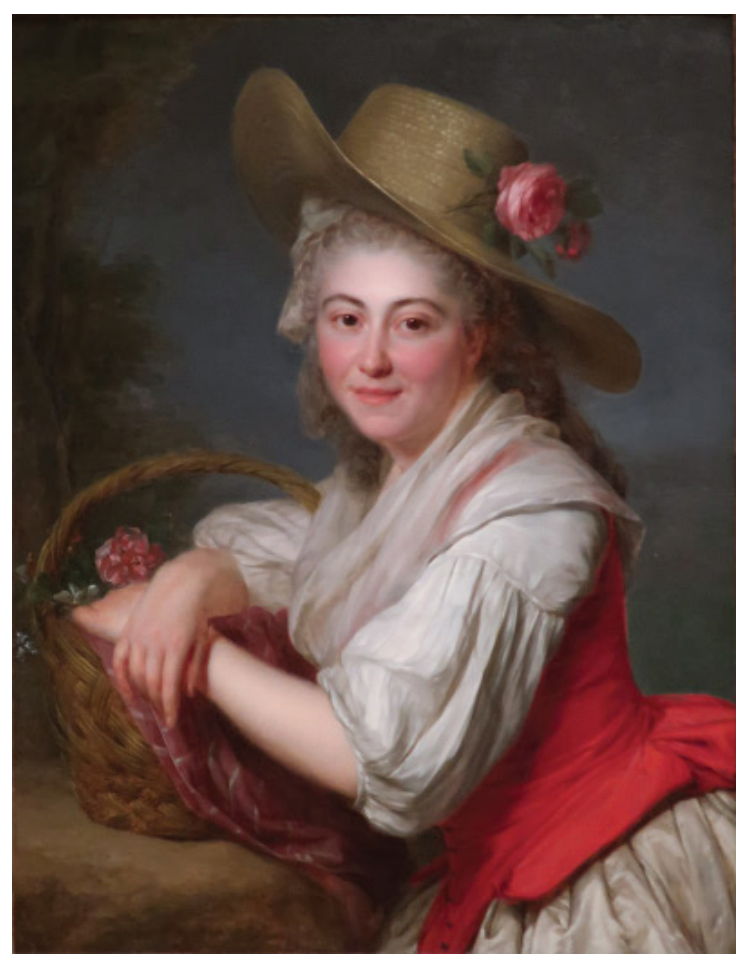

[Fig. 5] La Belle Jardinière, Antoine Vestier, 1787.

Oleo sobre tela, $81 \times 65 \mathrm{~cm}$. Museu de Arte de Phoenix, Phoenix. Disponível em: http://egallery.phxart.org/view/ objects/asitem/search@/1/title-asc?t:state:flow=5b268fed-a318-4346-8400-6d3145cd7cda

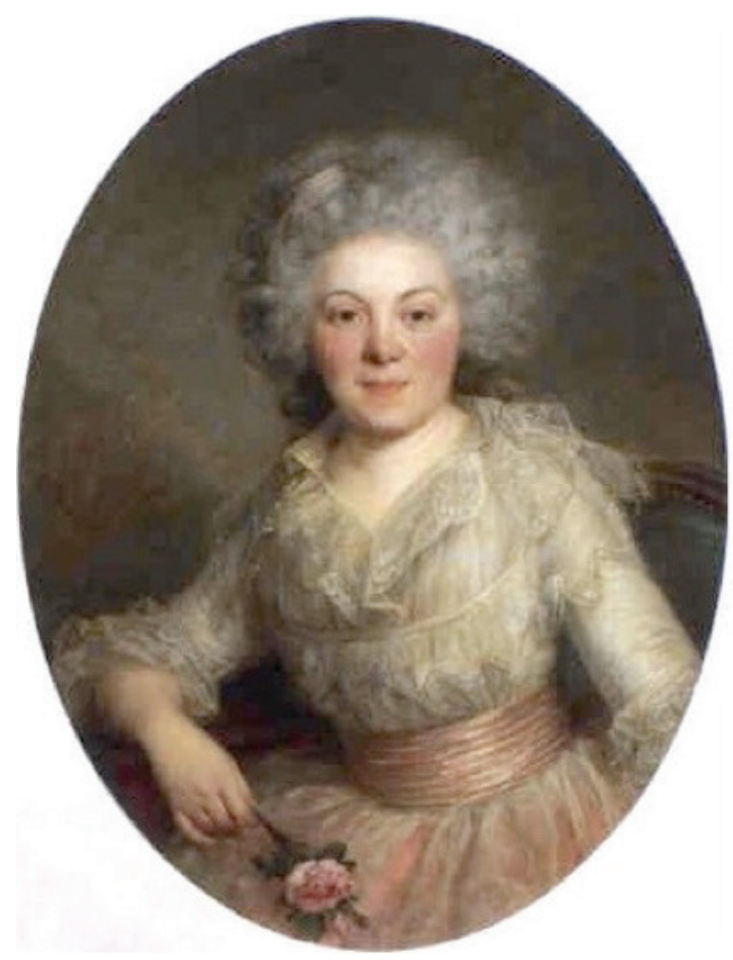

[Fig. 6] A Dama com a rosa, Antoine Vestier, 1787.

Oleo sobre tela oval, $80 \times 63 \mathrm{~cm}$. Coleção privada (última venda em 26/06/1991). Disponível em: http://www.artnet. com/artists/antoine-vestier/la-dame-a-la-rose-tOq5KIM4B8-pjEmhLzIOoA2

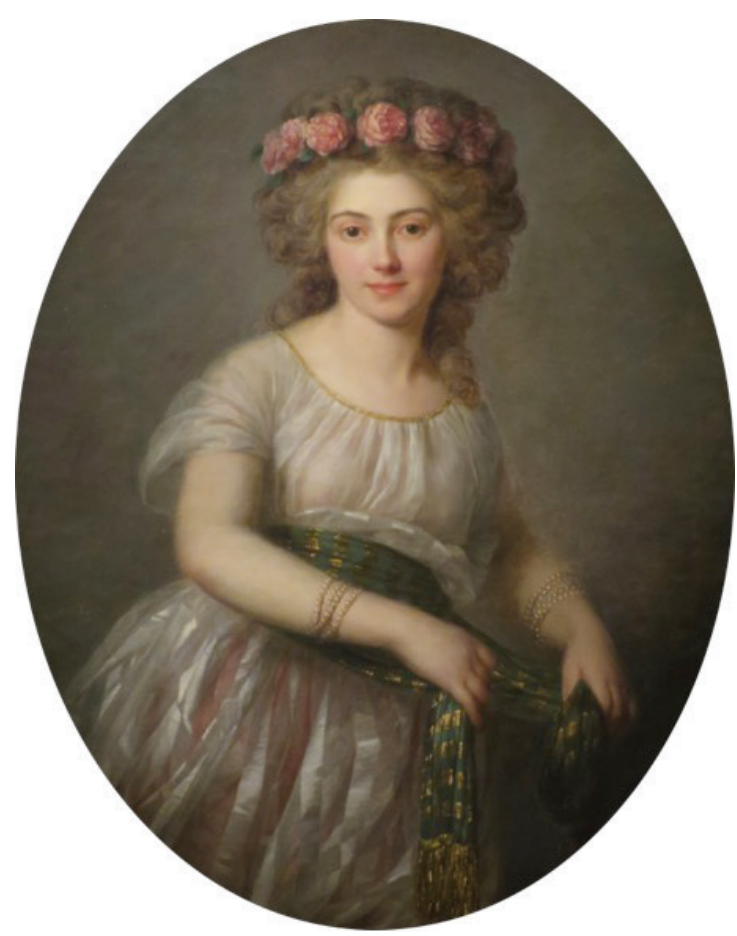

[Fig. 7] Madame Cromot de Fougy, Antoine Vestier, 1786. Óleo sobre tela, $96.5 \times 75.6 \mathrm{~cm}$.

Museu Norton Simon, Pasadena. Disponível em: https:// www.nortonsimon.org/art/detail/F.1983.16. 
cuidadosa apresentação de um álamo na lateral esquerda, enredado em sua base por um delicado roseiral e ladeado na face oposta por uma fonte, que caindo em pequenas cascatas abranda toda a representação, tudo enfim contribuindo para que o panorama determine o efeito da pintura. Já no quadro do museu americano, certamente de autoria de $V_{\text {estier }}{ }^{10}$, não há pormenores na caracterização, provida com uma paisagem que sobretudo não reforça o tema, sendo esta meramente emoldurante e tratada com menor atenção. O compósito dos tons fortes da tela possui algo de unímodo, um pouco rijo, talvez masculino em demasia - uma admoestação habitualmente feita a Vestier por seus críticos contemporâneos nas suas escolhas cromáticas - assim como nas texturas empregadas para representar as estofas, mesmo na leve musseline do fichu-menteur, que em sua austeridade esconde conservadoramente o decote. Na maneira como as expressões são executadas em ambas as damas transparece um claro contraste-enquanto a Bela Jardineira não transmite sentimentos imperscrutáveis, apenas um distanciamento cerimonioso com a retratação mais condicionada à veracidade fisionômica, a Dama com livro, jovem e emotiva em suas feições, nos propõe uma transposição, um planar de múltiplos sentimentos compreendidos entre pungência e graciosidade.

Já na A Dama com a rosa [Fig. 6], igualmente de 1787, o vestido é do mesmo tipo do retrato do MASP, uma robe chemise, ambas cingidas por largas faixas de cetim e guarnecidas de ornatos feitos de musseline alva e circunstados nos decotes. Entretanto, as diferenças de técnica pictórica e de resultado são palpáveis, pois enquanto na Dama com livro os tecidos são representados de maneira vívida e luzente, com contornos exatos e precisos, já Vestier optou por um esfumaçamento, não só nos tecidos como também nas representações da feição e dos ornamentos, muito mais próximo do "fluído" e do "efêmero" do que do "desenho impecável". ${ }^{11}$ Ademais, a utilização em ambas do mesmo penteado, usual no âmbito francês a partir da metade da década de 1780, evidencia as dissimilaridades entre as duas telas - o retrato do MASP, beneficiado de um composto muito mais harmonioso em seu conjunto entre as faixas acetinadas em tonalidade azul da prússia localizadas na cintura e na cabeça, de esmerada realização, distancia-se do da Dama com a rosa no que concerne a retratação dos mesmos adornos e cuja correspondência cromática com a flor titular evidencia uma abordagem de relação muito mais imediatista.

E ao compararmos com o quadro do MASP o Retrato de Madame Cromot de Fougy [Fig. 7] as diferenças são ainda mais contundentes. Vemos em ambas as telas, pintadas no mesmo período, duas jovens damas, em sua plena mocidade, ambas trajando robes chemises similares, ambas com o mesmo penteado en hérisson e frescamente coradas, com seus belos e escuros olhos marcantes, ambas sutilmente viradas de três-quartos

\footnotetext{
10 O quadro está assinado e datado embaixo à esquerda Vestier Pictor [...] 1787. PASSEZ, op. cit., p. 170.

11 Utilizados aqui alguns dos termos empregados pelo professor Coli em O Corpo da liberdade, ensaio título de sua obra publicada em 2010. COLI, op. cit., pp. 113 e 114 .
} 
à direita. No entanto tudo difere as 2 pinturas - enquanto na tela de Vestier a nobre francesa se anuncia com certa robustez, um pouco pesadamente, ainda que em um posicionamento levemente enlevado, com o pincel mostrando-se como que indeciso, tanto no desenho da feição e nos coloridos dos acessórios quanto nos contornos dos tecidos e na finalização do fundo uniforme levemente empastado, no quadro do MASP a figura da dama, mesmo que imóvel, é mais leve, mais delgada e fina, e sua feição, mesmo que distante, possui um charme e uma graciosidade distintos. A utilização da rosa, flor comumente atribuída ao viço e à mocidade, resulta distintamente nas duas pinturas, uma vez que na tela do MASP um ramo destas surge graciosamente ao lado da retratada, aludindo sutilmente à sua juventude, enquanto que no retrato da nobre francesa, ainda púbere à época da retratação, seu adornamento com uma densa coroa de rosas, colocada sólida e pesadamente sobre sua cabeça, de certa maneira envelhece-a em várias primaveras.

Efetivamente, ficam indicadas várias alteridades de técnica, procedimento e resultado entre estes retratos assinados por Vestier em comparação com a tela do MASP. As divergências são muitas, e acentuadas, e poderiam ser do mesmo modo assinaladas e identificadas em muitas das outras telas do pintor avallonês se defrontadas ao Retrato de Dama. De maneira determinante, esta tela não parece ser da mão de Vestier, e essa possibilidade é inclusive partilhada por diversos especialistas consultados por este autor.

O curador Pierre Rosenberg, antigo presidente-diretor do Museu do Louvre, quando questionado sobre a possibilidade da tela do MASP ser da mão de Vestier, assim respondeu:

Cher Monsieur, Rien n'est plus difficile que d'attribuer un portrait de la seconde moitié du XVIIle siècle. J'avais pensé à un peintre presque inconnu, Jean-Louis Voille, mais c'est une hypothèse dont je mesure toute la fragilité. Bien sincèrement,

Pierre Rosenberg

Em adição, Joseph Baillio, curador da Galeria Wildenstein e supervisor do Catálogo Raisonné de Vestier, e que, portanto, conhecia à época da realização deste a tela do MASP, assim descreveu:

Cher Monsieur, J'ai toujours hésité à attribuer ce portrait qu'on a donné —à tort à mon avis —à Antoine Vestier. A un certain moment, j'avais pensé à Robert Lefèvre, dont il pourrait s'agir d'une œuvre de jeunesse. Mais cela dit, je ne peux pas le dire d'une façon catégorique. Je regrette de ne pas pouvoir vous aider davantage. Bien cordialement, Joseph Baillio

Já o marchand Hubert Duchemin, cuja galeria em Paris é especializada em pintura francesa dos séculos 18 e 19, ponderou o seguinte, na resposta por ele enviada:

Cher Monsieur, Merci pour votre message et la photo qui l'accompagne. Effectivement votre tableau n'est pas de Vestier. II m'a fait penser instinctivement à Marie-Victoire 
Lemoine mais il est encore plus "provincial". Avec les sentiments dévoués, Hubert Duchemin

Laurence Kanter, curador-chefe na Yale Art Gallery, colocou da seguinte maneira, sem sugerir um nome para uma eventual atribuição, mas corroborando com os 3 especialistas citados:

Dear Mr. Merlino, Thank you for your message. Unfortunately, I may not be the right person to help you. I can, however, say that even from the photograph you sent it is necessary to agree that this painting is not by Antoine Vestier. The 3 alternative attributions suggested by Messrs. Baillio, Rosenberg, and Duchemin all indicate the relative hardness and flatness of this painting compared to Vestier's work. Whether any of these three attributions is accurate I could not say, nor could I suggest an alternative, but I do wish you the best of success in your research.

Laurence Kanter

Já Cassandra Albinson, curadora do Fogg Art Museum, instituição onde o retrato do MASP estaria hoje não fosse o súbito falecimento de CC Stillman, assim ponderou:

Dear Lorenzo, It was a pleasure to meet you. Here is the painter I was thinking of http:// collections.britishart.yale.edu/vufind/Record/1669206. Perhaps he is too late? But in any case, it might be hanging at the Yale Center when you go there. Cood luck! Yours sincerely, Cassandra

Erros de atribuição a Vestier ocorrem, inclusive, em diversos museus no mundo, onde incorreções são perpetradas e mantidas, mesmo após informações específicas e indicações contrárias - Passez alerta nomeadamente para "falsas atribuições de museus". Vestier produziu consideravelmente, decerto, e com suficiente qualidade e estilo próprios, mas certamente não na quantia estimada antes da elaboração de seu Catálogo Raisonné, em um disparate atributivo que superava o número de 420 obras, desde então reduzido para pouco mais de uma centena. Entretanto, esta delimitação não ocasionou um refreamento nesta espécie de práxis de autoria irrefreada pois ainda hoje não é raro encontrar obras propostas em leilões de casas renomadas com um incauto e irrefletido assentimento "Antoine Vestier", provavelmente como forma de chancelar pinturas de composição anônima e facilitar comercializações.

Não ocorreu, entretanto, entre os especialistas consultados, qualquer conformação de concordância acerca de uma reatribuição da pintura do MASP, e nem ao menos uma recorrência de algum dos nomes propostos. Um nome sugerido por um não é aceito por outro, uma possibilidade emitida por aquele é disputada por este. Como bem colocado pelo Sr. Rosenberg e precisamente apontado pelo professor Coli, ocorre uma evidente dificuldade em se atribuir um retrato como esse, 
fato claramente evidenciado pelo rol extremamente diverso das várias sugestões atributivas, e bastante provavelmente a questão jamais se tornará plenamente estabelecida. Mas em um aspecto todos os especialistas emitiram julgamento idêntico e de modo praticamente definitivo - o Retrato de dama com livro junto a uma fonte não é de autoria de Antoine Vestier. 


\section{Referências bibliográficas}

BLANC, Olivier. Portraits de femmes: artistes et modèles à l'époque de Marie-Antoinette. Paris: Éditions Didier Carpentier, 2006.

BOUCHER, François. História do vestuário no Ocidente. São Paulo: Cosac \& Naify, 2012.

BURR, Anna Robeson. The Portrait of a Banker: James Stillman, 1850-1918. Nova lorque: Duffield \& Company, 1927. Disponível em: <https://babel.hathitrust.org/cgi/pt?id=uc1.b3486480;view=1up;seq=11>. Acesso em 22 de maio de 2016.

Catálogo do Museu de Arte de São Paulo Assis Chateaubriand. São Paulo: Prêmio Editorial, 1998.

CHÉRY, Philippe. Lettres analitiques, critiques et philosophiques, sur les tableaux du Sallon de 1791. Paris: [s.n.], 1791. Disponível em: https://gallica.bnf.fr/ark:/12148/btv1b8458348s?rk=107296;4>. Acesso em 22 de setembro de 2017.

COLI, Jorge. O Corpo da Liberdade. São Paulo: Cosac \& Naify, 2010.

COOPER, Douglas. Great Private Collections. Londres: Weidenfeld and Nicolson, 1963.

FOULON DE VAULX, André. Antoine Vestier, 1740-1824, notes et renseignements. In: Le Carnet Historique et Littéraire, tome VII (Janvier-Février-Mars 1901). Paris: Aux Bureaux de la Revue, 1901. Disponível em: <http://gallica.bnf.fr/ ark:/12148/bpt6k5820496r/f8.item.r=vestier>. Acesso em 2 de outubro de 2016.

HALE, Nancy. Mary Cassatt: A biography of the great American painter. Nova lorque: Doubleday \& Company, 1975.

KLEPPER, Michael; GUNTHER, Robert. The Wealthy 100: From Benjamin Franklin to Bill Gates - A Ranking of the Richest Americans, Past and Present. Nova lorque: Citadel Press, 1996.

LEBAS, Catherine e JACQUES, Annie. La Coiffure en France du Moyen âge à nos jours. Paris: Delmas, 1979.

LEVEY, Michael. Pintura e Escultura na França 1700-1789. São Paulo: Cosac \& Naify, 1998.

. Rococo to Revolution: Major Trends in Eighteenth-Century Painting. Londres: Thames and Hudson, 1966.

MATHEWS, Nancy Mowll. Mary Cassatt: A Life. New Haven e Londres: Yale University Press, 1994.

MCKOWN, Robin. The World of Mary Cassatt. Nova lorque: Thomas Y. Crowell Co., 1972.

NIZET, Charles. Les Vestier. In: Congrès archéologique de France: séances générales tenues en 1907 par la Société française d'archéologie. Caen: H. Delesques, 1908. Disponível em: <https://gallica.bnf.fr/ark:/12148/bpt6k35676p/ f910.item.r=vestier>. Acesso em 14 de fevereiro de 2016.

PASSEZ, Anne-Marie. Antoine Vestier. Paris: La Bibliothèque des Arts, Fondation Wildenstein, 1989.

RIBEIRO, Aileen. Dress in Eighteenth-Century Europe. New Haven e Londres: Yale University Press, 2002.

SUEUR, Jean-Claude. Le portraitiste Antoine Vestier (1740-1824). Rueil-Malmaison: [s.n.], 1974.

The Stillman Collection of Paintings, on Exhibition \& Sale at The American Art Galleries, New York, 1927. Nova lorque: American Art Association Inc, 1927. Disponível em: <https://archive.org/stream/importantpaintinooamer_1\#page/n3/mode/2up >. Diversos acessos.

WINKLER, John Kennedy. The first billion; the Stillmans and the National City Bank. Nova lorque: The Vanguard Press, 1934. Disponível em: <https://www.google.com.br/ url?sa=t\&rct=j\&q=\&esrc=s\&source=web\&=\&ved=0ahUKhttp\%3A\%2F\%2Fwww.dli.ernet.in\%2Fbitstrnce\%3D1\%2 6isAllowed\%3Dy\&usg=AFQjCNHrltRKzOsEiZB4-dqRzFfWe2Wdw\&sig2=b-UbByhm6zqEVUR1ladQA\&b>. Acesso em 2 de maio de 2016. 